\title{
Glycation of very low density lipoprotein from rat plasma impairs its catabolism
}

\author{
J. C. L. Mamo, L. Szeto and G. Steiner \\ Department of Medicine, Division of Endocrinology and Metabolism, Toronto General Hospital, Ontario, Canada
}

\begin{abstract}
Summary. Rat VLDL were glycated in vitro in the presence or absence of a reducing agent. Prior to glycation, the VLDL triglyceride was endogenously radiolabelled with $\left[{ }^{3} \mathrm{H}\right]$-oleic acid. Post glycation the VLDL B-apoprotein was exogenously radiolabelled with [ $\left.{ }^{131}\right] \mathrm{I}$. The double labelled VLDL was then injected into normal rats and the decline in plasma radioactivity of the two isotopes was used as a measure of triglyceride and particle clearance. VLDL glycated in either the presence or absence of reducing agent exhibited a significantly slower removal of triglyceride and apoprotein B compared to normal VLDL. The ability of glycated VLDL triglyceride to act as substrate for lipoprotein lipase and hepatic lipase was examined. Increasing concentrations of normal and glycated VLDL triglyceride were
\end{abstract}

incubated with post-heparin plasma. The kinetics of triglyceride hydrolysis were determined in a manner analagous to Michaelis-Menten analysis. Glycated VLDL was found to be poorer than normal VLDL as a substrate for lipoprotein lipase. Glycation of VLDL appears to interfere with the lipolysis of its triglyceride. This may explain the delayed clearance of glycated VLDL triglyceride in vivo. Glycation also extended the mean plasma residence time of the VLDL particle. These factors may, in part, contribute to the hypertriglyceridaemia observed in subjects with diabetes mellitus.

Key words: VLDL, glycation, triglyceride, kinetics, lipase, rat.
Atherosclerosis is the major cause of morbidity and mortalitiy among diabetic patients [1]. The mechanisms by which diabetes mellitus accelerate this are multifactorial, but may include perturbations in lipoprotein metabolism bought about by the post-translational non-enzymatic glycation of the plasma lipoprotein proteins [2-4].

Curtiss and Witztum demonstrated that a number of apoproteins were glycated in hyperglycaemic subjects with diabetes [5], the majority of which were associated with very low density lipoproteins (VLDL). It is plausible to associate the hypertriglyceridaemia observed in subjects with diabetes with an impaired VLDL catabolism due to protein glycation. However, whether or not glycated apoproteins modify the catabolic behaviour of lipoproteins in hyperglycaemic diabetic patients remains to be demonstrated, particularly for the triglyceride rich VLDL.

The aim of this study was to determine whether apoprotein glycation had the potential to interfere with VLDL-triglyceride catabolism. To examine this, normal rat VLDL was glycated in vitro. The rate of endogenously radiolabelled VLDL-triglyceride and VLDL particle (exogenously radiolabelled apoprotein B) clearance was then determined in vivo. In addition, the ability of glycated VLDL-triglyceride to act as substrate for the endothelial lipases (lipoprotein lipase and hepatic lipase) was also examined. We report here that glycated VLDL is not catabolized as efficiently as native VLDL.

\section{Materials and methods}

\section{Radiolabelling of rat VLDL-triglyceride}

To each $\mathrm{ml}$ of ethanolic $\left[9,10-{ }^{3} \mathrm{H}(\mathrm{N})\right]$-oleic acid $(19 \mathrm{mg} / \mathrm{ml}$, $250 \mu \mathrm{Ci} / \mathrm{ml}), 1.1 \mathrm{ml}$ of $0.27 \mathrm{~mol} / \mathrm{KOH}$ was added and mixed thoroughly. The ethanol was evaporated at $70^{\circ} \mathrm{C}$ under a constant stream of high purity nitrogen. Whilst mixing, $4 \mathrm{ml}$ of $26 \%$ bovine serum albumin was added to the fatty acids. The oleic acid-albumin complex was then immediately injected into rats to radiolabel the VLDL-triglyceride.

Male Wistar rats of body weight $300-350 \mathrm{~g}$ were starved for at least $14 \mathrm{~h}$. Water was available ad libitum. Rats were bled under pentobarbital anaesthesia ( $65 \mathrm{mg} / \mathrm{kg}$ body weight) from the abdominal aorta, $40 \mathrm{~min}$ after injection of $100 \mu \mathrm{Ci}$ of the $\left[{ }^{3} \mathrm{H}\right]$-oleic acid complex into the femoral vein. Blood was collected into tubes containing EDTA $(1 \mathrm{~mol} / \mathrm{l})$ and plasma was separated after low speed centrifugation. Phenylmethylsulphonylfluoride and sodium azide were added to plasma to give a final concentration of $0.02 \mathrm{~mol} / \mathrm{l}$ and $0.002 \mathrm{~mol} / \mathrm{l}$ respectively. VLDL was isolated at density $1.006 \mathrm{~g} / \mathrm{ml}$ by ultracentrifugation (Beckman model L8-70, Toronto, Ontario, $\mathrm{Ca}$ nada), using a Beckman 70.1 Ti rotor at $108000 \mathrm{~g}$ for $18 \mathrm{~h}$ at $20^{\circ} \mathrm{C}$. The VLDL preparation was washed by recentrifugation through a $\mathrm{NaCl}$ solution of density $1.006 \mathrm{~g} / \mathrm{ml}$. We established in previous studies that more than $98 \%$ of the ${ }^{3} \mathrm{H}$ label was associated with the triglyceride of VLDL [6].

In some experiments the VLDL B apoprotein was also radiolabelled with ${ }^{131} \mathrm{I}$ according to the modified method of McFarlane et al. [7]. This was done after the glycation procedure. Free ${ }^{131} \mathbf{I}$ was removed by passage through a Sephadex G50 (fine) column, followed by extensive dialysis against $0.15 \mathrm{mmol} / \mathrm{l} \mathrm{NaCl}$. The distribution of the ${ }^{131}$ I label in the VLDL lipids and protein components was assessed according to established procedures [7-8]. 


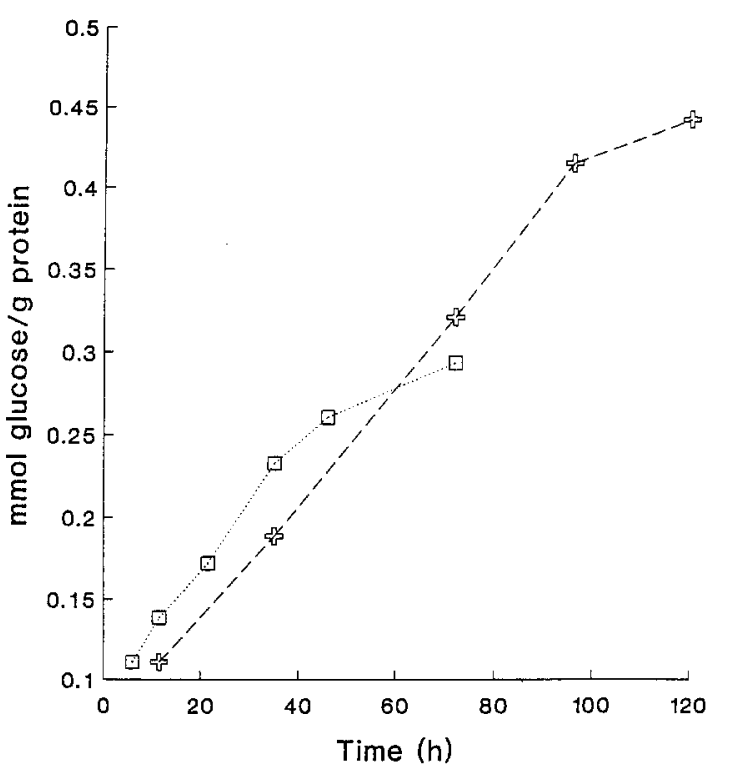

Fig. 1. Glucose incorporation into VLDL-protein with time. Radioactive glucose was incubated with VLDL in the absence (f) and presence $(\square)$ of reducing agent. Results are the mean of two experiments

\section{Glycation of VLDL}

Radiolabelled VLDL $(700 \mu \mathrm{g}-1000 \mu \mathrm{g})$ sterilized by passage through a $0.22 \mu \mathrm{m}$ low protein binding filter (Millex-GS, Millipore, Boston, Mass., USA) was non-enzymatically glycated in the presence of a sterilized $200 \mathrm{mmol} / \mathrm{l} \mathrm{D}$-glucose solution (final volume $3 \mathrm{ml}$ ). The assay solution contained $130 \mathrm{nmol} / \mathrm{l}$ sodium azide. Glycation was done at $37^{\circ} \mathrm{C}$ for $72 \mathrm{~h}$, in a shaking water bath ( 60 cycles/min), unless stated otherwise. A second VLDL fraction was glycated under identical conditions but with the inclusion of a reducing agent (sodium cyanoborohydride, $\mathrm{NaCNBH}_{3}$ ), $200 \mathrm{mmol} / \mathrm{l}$ ). A third VLDL fraction was incubated with $0.15 \mathrm{~mol} / \mathrm{l}$ $\mathrm{NaCl}$ for an equivalent period of time and is referred to as the control VLDL fraction. The VLDL's were kept under a nitrogen atmosphere and in the dark during the glycation procedure. At the end of the $72 \mathrm{~h}$ incubation period, the VLDL fractions were collected and dialysed separately against 2 litres of $0.15 \mathrm{~mol} / 1$ $\mathrm{NaCl}, \mathrm{pH} 7.4$ for a minimum of $16 \mathrm{~h}$ at $4^{\circ} \mathrm{C}$. The VLDL fractions were then used immediately for the lipolysis or turnover studies.

The rate of VLDL-protein glycation was determined by examining the incorporation of radiolabelled $\mathrm{D}$-glucose ${ }^{3} \mathrm{H}$ $(0.1775 \mu \mathrm{Ci} / \mathrm{mmol})$ vs time $(270 \mu \mathrm{Ci} / \mathrm{mg}$ protein $)$. D-glucose $-3-{ }^{3} \mathrm{H}$ was purified according to the method of Schleicher et al. [4]. Aliquots of $200 \mu \mathrm{l}$ of the VLDL incubation mixture were taken at selected time intervals. VLDL-protein was precipitated and washed as described by Witztum et al. [9]. The amount of radioactive glucose which was incorporated into total VLDL protein was determined by directly counting the radioactivity in the precipitate (LKB model 1219 liquid scintilation counter, Toronto, Ontario, Canada). Glucose incorporation into the various apoproteins was determined by separating the apoproteins by sodium dodecyl sulphate polyacrylamide gel electrophoresis (SDS-PAGE) (3-10\% polyacrylamide gradient gels, Isolab Inc. Cleveland, Ohio, USA), and measuring the amount of radioactivity associated with each of the proteins. VLDL was lyophilized and delipidated according to the method of Herbert et al. [10]. To obtain a clearer separation of the apoprotein isoforms, apoprotein B100, B95 and B48 were separated by $3 \%$ SDS-PAGE [11] and soluble proteins (apoproteins $\mathrm{E}$ and $\mathrm{C}$ ) by isoelectric gel focussing electrophoresis (IEF) [12].

\section{VLDL-triglyceride lipolysis studies with rat post-heparin plasma}

The ability of glycated and non-glycated rat VLDL-triglyceride to be lipolyzed by lipases in rat post-heparin plasma (PHP) was examined. It is not possible to calculate $\mathrm{K}_{\mathrm{m}}$ and $\mathrm{V}_{\text {max }}$ for a lipoprotein substrate and with an impure enzyme. Therefore, we measured the rate of lipolysis at various VLDL concentrations and used an approach analagous to traditional Michaelis-Menten kinetics to calculate the half maximal rate of VLDL-triglyceride lipolysis, termed "apparent $\mathrm{K}_{\mathrm{m}}$ " and the point at which post-heparin plasma was saturated with substrate, termed "apparent $V_{\text {max }}$ ". In a typical VLDL-triglyceride lipolysis study the assay mixture contained $50 \mu \mathrm{l}$ of a 3.5 in 5 dilution (in $0.15 \mathrm{~mol} / \mathrm{NaCl}$ ) of PHP, $300 \mu \mathrm{l}$ of VLDL-triglyceride $(1 \mathrm{mmol} / \mathrm{l}$ triglyceride), $25 \mu \mathrm{l}$ of heat inactivated rat serum and $325 \mu \mathrm{l}$ of $0.15 \mathrm{~mol} / 1 \mathrm{NaCl}$. Incubation was done at $37^{\circ} \mathrm{C}$ in a shaking water bath for $7.5 \mathrm{~min}$. At the end of the incubation time the assay was stopped by the addition of $3.5 \mathrm{ml}$ of isopropanol : hexane: $0.5 \mathrm{~mol} / \mathrm{l} \mathrm{H}_{2} \mathrm{SO}_{4}$ (40:10:1). Then $2.1 \mathrm{ml}$ of hexane followed by $1.4 \mathrm{ml}$ of $0.05 \mathrm{~mol} / 1$ $\mathrm{H}_{2} \mathrm{SO}_{4}$ were added. The tubes were capped and shaken vigorously for $10 \mathrm{~min}$. After low speed centrifugation, $2.1 \mathrm{ml}$ of the upper phase was transferred to tubes containing $1.05 \mathrm{ml}$ of $0.1 \mathrm{~mol} / 1 \mathrm{NaOH}$ in ethylene glycol. The tubes were capped, shaken vigorously for $10 \mathrm{~min}$ and centrifuged. $700 \mu \mathrm{l}$ of the upper phase was transferred into vials containing scintillant. Recovery was monitored using an internal standard which was added to the PHP at the start of the assay $\left({ }^{14} \mathrm{C}\right.$ palmitic acid, $\left.0.1 \mu \mathrm{Ci} / \mathrm{ml} \mathrm{PHP}\right)$. Radioactivity was counted in an LKB (model 1219) liquid scintillation counter in dual label mode with auto quench correction. To determine the contribution of lipoprotein lipase (LPL) and hepatic lipase (HL) to total lipolysis, HL was determined in a second tube which contained the same components in the incubation medium except that the rat serum was omitted and the $0.15 \mathrm{~mol} / \mathrm{l} \mathrm{NaCl}$ was replaced with $350 \mu \mathrm{l}$ of $3 \mathrm{~mol} / \mathrm{l}$ $\mathrm{NaCl}$, to give a final salt concentration of $1 \mathrm{~mol} / \mathrm{l}$. Under these conditions LPL is not active [13]. LPL was calculated as the difference between total lipase activity and HL activity. For some experiments the concentration of VLDL-triglyceride, PHP or time of incubation may have differed. These are described in the text.

\section{In vivo kinetic studies}

VLDL-triglyceride kinetics were determined by injecting VLDLtriglyceride $\left[{ }^{3} \mathrm{H}\right.$-oleate] into the femoral vein of $330-370 \mathrm{~g}$ rats (under pentobarbital anaesthesia) and monitoring the decline in plasma triglyceride radioactivity. The mass of VLDL triglyceride injected was never more than $5 \%$ of the recipients total plasma triglyceride pool. At 1-2 min intervals $400 \mu$ l blood samples were drawn for up to $14 \mathrm{~min}$, from an indwelling polyethylene cannula (PE-50, internal diameter $0.58 \mathrm{~mm}$ ) in the opposite femoral vein. After each blood sampling the cannula was flushed with $0.15 \mathrm{ml}$ of $0.15 \mathrm{~mol} / \mathrm{l}$ $\mathrm{NaCl}$. Plasma was collected after centrifugation at $3000 \mathrm{rev} / \mathrm{min}$ for $10 \mathrm{~min}$ at $4^{\circ} \mathrm{C}$. Radiolabelled triglyceride was extracted from $0.2 \mathrm{ml}$

Table 1. The half-life for $\left[{ }^{3} \mathrm{H}\right]$-triglyceride of normal and glycated VLDL

\begin{tabular}{lrc}
\hline & & Half-life (T1/2) (min) \\
\hline Normal VLDL-TG & $(10)$ & $6.88 \pm 0.45$ \\
$\begin{array}{l}\text { Reductively glycated } \\
\text { VLDL-triglyceride }\end{array}$ & $(9)$ & $12.36 \pm 1.19^{\mathrm{a}}$ \\
$\begin{array}{l}\text { Non-reductively glycated } \\
\text { VLDL-triglyceride }\end{array}$ & $(7)$ & $11.31 \pm 1.36^{\mathrm{a}}$ \\
\hline
\end{tabular}

Endogenously radiolabelled VLDL was glycated in the presence or absence of a reducing agent. The VLDL's were injected into normal recipient rats and the clearance rate determined. $(n)=$ number of recipient animals. Half-life is min \pm SEM. ${ }^{a}$ denotes significance vs control at $p<0.001$ 


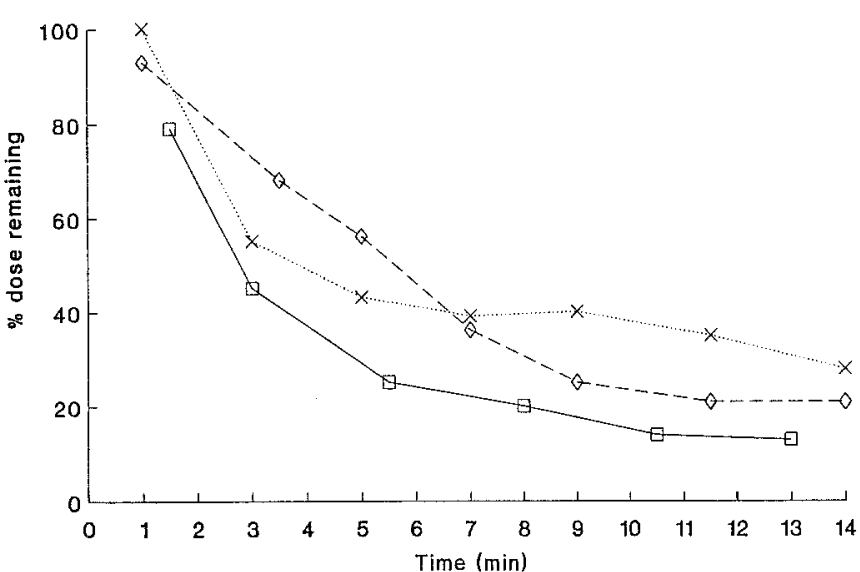

Fig. 2. Typical clearance of control VLDL-triglyceride ( $\square$ ), reductively glycated VLDL-triglyceride $(x)$ and non-reductively glycated VLDL-triglyceride $(\diamond)$ in normal rats

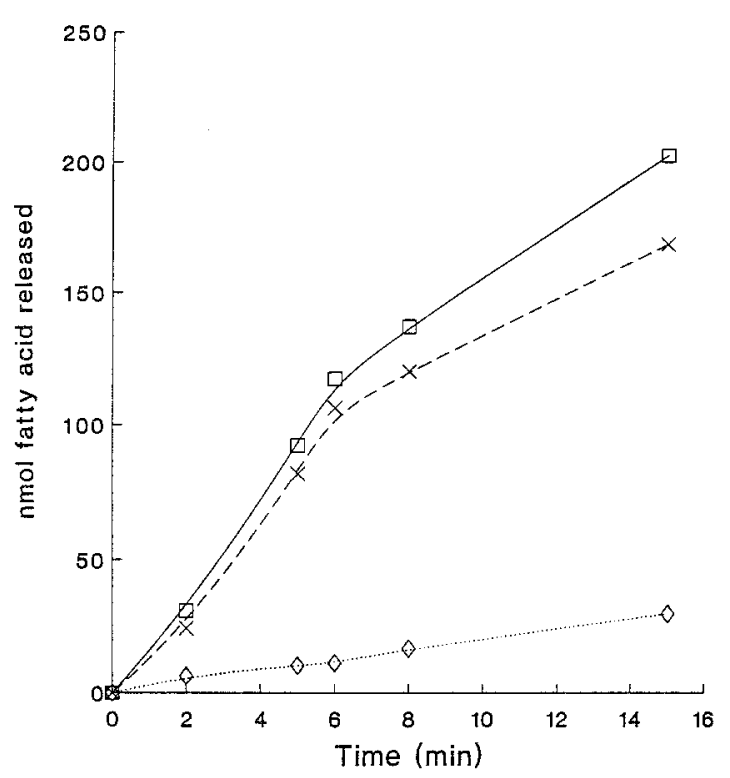

Fig.3. Hydrolysis profile of normal VLDL-triglyceride lipolyzed with post-heparin plasma from a normal rat with time. Total activity $(\square)$ and hepatic lipase activity $(\diamond)$ were measured. Lipoprotein lipase activity $(x)$ was determined by the difference between the total and hepatic lipase activities

plasma with $4.8 \mathrm{ml}$ of isopropanol, in the presence of $2 \mathrm{~g}$ heat reactivated Zeolite (Sigma, St. Louis, Mo, USA). Preliminary investigations showed that under these conditions, over $97 \%$ of the label in the isopropanol was in the triglyceride. Then $2.5 \mathrm{ml}$ of the isopropanol extract was dried under nitrogen and radioactivity counted in scintillant, using an LKB liquid scintillation counter (model 1219) with auto quench correction. Clearance of radiolabelled VLDL-triglyceride was monoexponential in nature. Half-life of triglyceride was calculated after exponential regression analysis. The kinetics of VLDL-apoprotein B and VLDL-triglyceride were simultaneously determined in recipient rats by monitoring the rate of decline in plasma radioactivity of double labelled VLDL $\left({ }^{3} \mathrm{H}\right.$-triglyceride and ${ }^{131} \mathrm{I}$ apoprotein B). Eight $300 \mu \mathrm{l}$ blood samples were taken over a $30 \mathrm{~min}$ period. Apoprotein $B$ was specifically precipitated directly from plasma as previously described [14]. Triglycerides were extracted prior to counting. Radioactivity associated with either protein or lipid was determined using standard channels ratio mode, in an LKB liquid scintillation counter with auto quench correction. The mean residence time (MRT) of triglyceride and apoprotein B were determined in preference to half-life, because over a $30 \mathrm{~min}$ period the clearance patterns were of a dual exponential nature (at least with respect to the control VLDL).

\section{Statistical analysis}

Each batch of PHP contained a different amount of lipase activity, and so the calculated "apparent $\mathrm{K}_{\mathrm{m}}$ " and "apparent $\mathrm{V}_{\max }$ " were not normally distributed. Therefore, the non-parametric Mann-Whitney test was used to compare the VLDL-triglyceride lipolysis studies. The in vivo kinetic data was compared by analysis of variance.

\section{Results}

\section{Rate of lipoprotein glycation}

The rate of VLDL-protein glycation was determined by monitoring the incorporation of $\left[{ }^{3} \mathrm{H}\right]$-glucose. Figure 1 shows glucose incorporation in the presence or absence of a reducing agent $\left(\mathrm{NaCNBH}_{3}, 200 \mathrm{~mol} / \mathrm{l}\right)$. Glycation was linear for at least $72 \mathrm{~h}$ and not influenced by cyanoborohydride.

\section{In vivo VLDL-triglyceride kinetics}

Initially, we wanted to determine whether glycation of VLDL protein had the potential to interfere with removal of triglyceride in vivo. VLDL-triglyceride from normal rats was endogenously radiolabelled with $\left[{ }^{3} \mathrm{H}\right]$-oleate prior to glycation. The labelled VLDL-triglyceride was then injected into normal recipients and the rate of decline in plasma triglyceride radioactivity was used to determine the half-life. Figure 2 shows an example of the clearance of VLDL-triglyceride profile obtained when the different VLDL preparations were injected into normal recipient rats. Table 1 shows that triglyceride of VLDL that had been glycated with or without reducing agent remained in the plasma compartment about twice as long as that of normal VLDL.

\section{In vitro lipolysis studies}

An impaired removal of VLDL-triglyceride may be due to two possible mechanisms. The first is that the triglyceride of glycated VLDL particles is less able to be lipolysed by endothelial triglyceride lipases. Second, VLDL or their remnants (which are in the greater part depleted of triglyceride) may be cleared less readily by receptor and/or non-receptor mediated processes. To test the first of these, we did a study analogous to those used to obtain Michaelis-Menten kinetics. The concentration of VLDL-triglyceride at which rates of lipolysis were half maximal ("apparent $\mathbf{K}_{\mathrm{m}}$ ") as well as the concentration at which lipolysis was maximized ("apparent $V_{\max }$ ") for PHP- LPL and HL from normal rats were determined.

The VLDL-triglyceride lipase study was first characterized prior to "apparent $\mathrm{K}_{\mathrm{m}}$ and $\mathrm{V}_{\max }$ " determinations. Figure 3 shows a typical curve of the time course of hydro- 


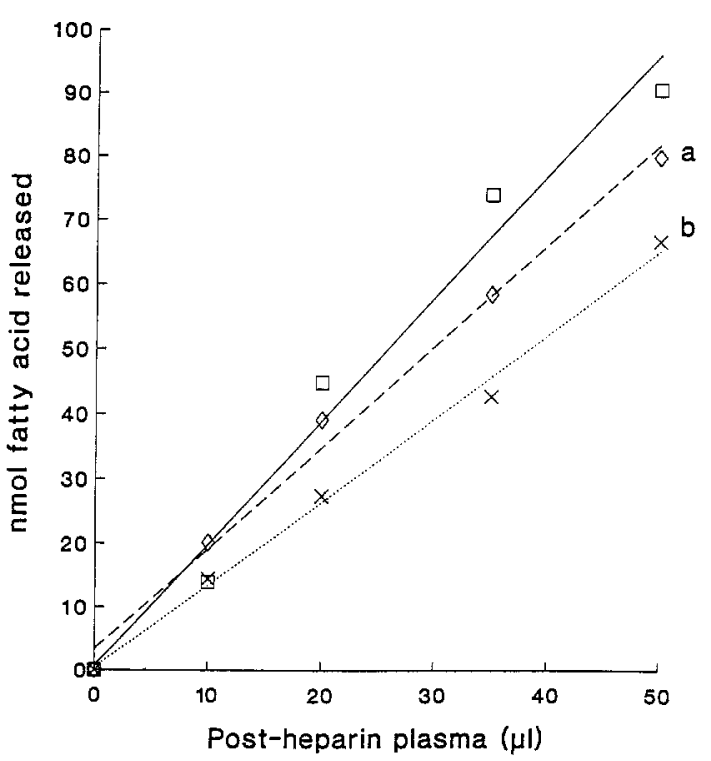

Fig. 4. Mean fatty acids released for normal VLDL-triglyceride $(\square)$, reductively glycated VLDL $(x)$ and non-reductively glycated VLDL $(\diamond)$ with increasing concentration of post-heparin plasma. Results are the mean of four experiments. Significance at $p<0.025$ and $p<0.010$ vs normal VLDL-triglyceride denoted by (a) and (b) respectively

lysis, obtained by incubating normal VLDL-triglyceride with PHP-LPL and -HL. Activities were linear until $6 \mathrm{~min}$ at $37^{\circ} \mathrm{C}$, but thereafter LPL diminished at a slow rate. An identical qualitative profile was obtained with both reductive and non-reducitve glycated VLDL.

VLDL-triglyceride at constant concentration was incubated with increasing concentrations of PHP-lipases. Lipolysis was found to be linear over a fivefold increase in the PHP concentration irrespective of the type of VLDLtriglyceride used as substrate (Fig. 4). The rate at which glycated and normal VLDL-triglyceride were hydrolyzed differed however, as shown in Table 2. Glycated VLDLtriglyceride, irrespective of whether this was prepared in the presence or absence of a reducing agent was lipolyzed by PHP-LPL at a slower rate (measured as the rate of product released). On the other hand, VLDL-triglyceride glycated in the absence of $\mathrm{NaCNBH}_{3}$ exhibited a quicker rate of HL mediated hydrolysis, than did normal control VLDL-triglyceride.

Increasing concentrations of VLDL-triglyceride were lipolyzed with PHP. Figure 5 is an example of LinweaverBurk plots for normal and glycated VLDL against PHPLPL. Table 3 a lists the $K_{m}$ data obtained for different enzyme sources. The LPL "apparent $\mathrm{K}_{\mathrm{m}}$ " was significantly higher for glycated VLDL than for non-glycated VLDL. This was independent of the two different glycation procedures. On the other hand, there was no significant trend for the "apparent $V_{\max }$ " of LPL and the different VLDL-triglyceride preparations (Table $3 \mathrm{~b}$ ). In addition, there was no detectable difference in the "apparent $\mathrm{K}_{\mathrm{m}}$ " for glycated VLDL and PHP-HL. In some instances the glycated particles appeared to be resistant to the activity of this enzyme whereas on other occassions the glycation appeared to enhance the rate of hydrolysis.

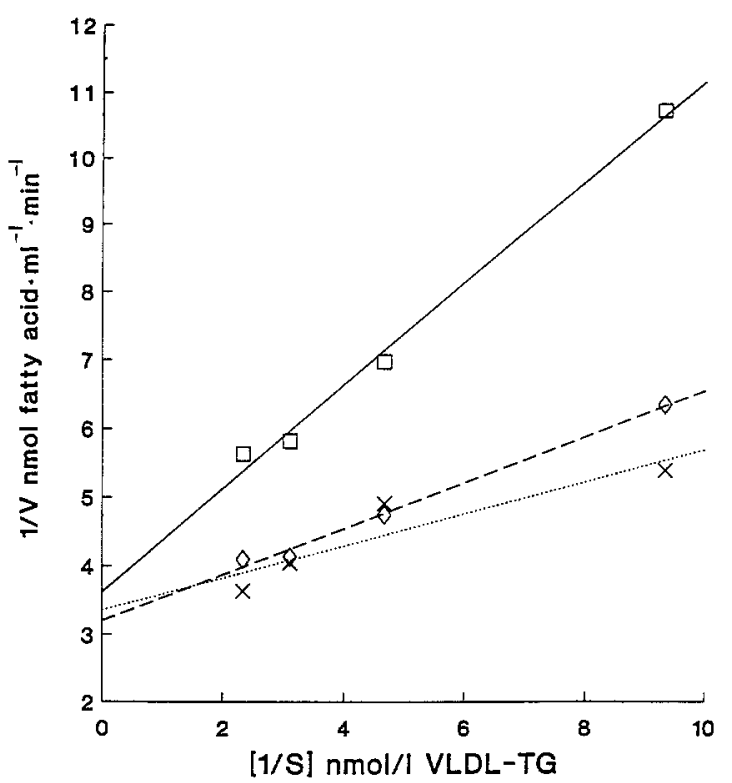

Fig.5. Linweaver-Burk plots obtained for normal VLDL-triglyceride $(\square)$, reductively glycated VLDL $(x)$ and non-reductively glycated VLDL $(\diamond)$ against post-heparin plasma (PHP) from one normal rat. $1 / \mathrm{V}=(\text { rate of product released per } \mathrm{ml} \text { PHP per min })^{-1}$. $1 / \mathrm{S}=(\text { concentration of substrate })^{-1}$

In vivo kinetics of $V L D L$-triglyceride and VLDL-apoprotein $B$

The delayed clearance of glycated VLDL-triglyceride may, in addition to perturbations in the lipolytic cascade, be due to slower particle removal mechanisms. In order to test this, the triglyceride of VLDL, (both normal and glycated) was endogenously labelled. Subsequently, the protein component was labelled with ${ }^{131} \mathrm{I}$. The radiolabelled VLDL was then injected into recipient rats and the decline in plasma radioactivity of the two isotopes determined. Apoprotein $\mathrm{B}\left[{ }^{131} \mathrm{I}\right]$ radioactivity clearance was

Table 2. The rates of lipolysis of normal and glycated VLDL-triglyceride

\begin{tabular}{|c|c|c|c|c|c|}
\hline \multirow{2}{*}{$\begin{array}{l}\text { Substrate } \\
\text { (VLDL-TG) } \\
\text { Enzyme activity } \\
\text { Post-heparin } \\
\text { plasma batch no. }\end{array}$} & Normal & \multicolumn{2}{|c|}{$\begin{array}{l}\text { Reductively } \\
\text { glycated }\end{array}$} & \multicolumn{2}{|c|}{$\begin{array}{l}\text { Non-reductively } \\
\text { glycated }\end{array}$} \\
\hline & $\begin{array}{l}\text { LPL HL } \\
(\mathrm{nmol} / \mathrm{min})\end{array}$ & $\begin{array}{l}\text { LPL } \\
(\% \text { of } n\end{array}$ & $\begin{array}{l}\mathrm{HL} \\
\text { ormal lip }\end{array}$ & lysis & \\
\hline 1 & $\begin{array}{ll}1.726 & 0.157\end{array}$ & 41 & 123 & 49 & 240 \\
\hline 2 & $2.738 \quad 0.260$ & 74 & 94 & 71 & 206 \\
\hline 3 & 1.077 & 83 & 65 & 81 & 140 \\
\hline 4 & $1.231 \quad 0.278$ & 73 & 70 & 79 & 143 \\
\hline Mean \pm SEM & & $68 \pm 9^{\mathrm{a}}$ & $88 \pm 13$ & $70 \pm$ & $163 \pm 21^{a}$ \\
\hline
\end{tabular}

VLDL-triglyceride was incubated with increasing amounts of postheparin plasma from normal rats. Lipoprotein lipase (LPL) activity was determined as the total hydrolase component less the hepatic lipase (HL) activity. The rate of normal VLDL-triglyceride lipolysis is given as the slope of product released (fatty acid). The rate of lipolysis of reductively glycated VLDL and non-reductively glycated VLDL for each source of post-heparin plasma is expressed as a percentage of the rate obtained for normal VLDL. ${ }^{a}$ denotes significance at $p<0.05$ 

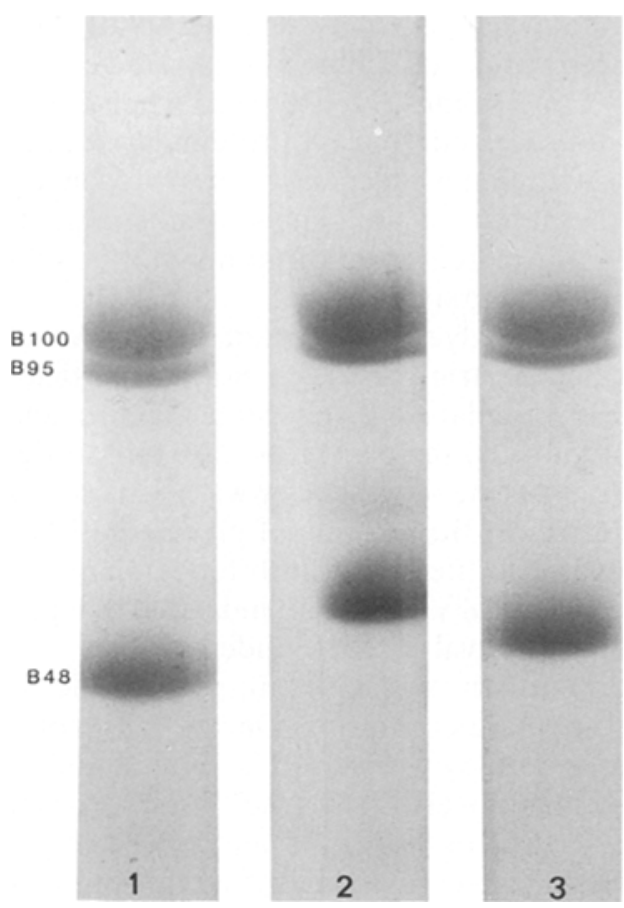

Fig.6. Lanes 1-3 show apoprotein B for normal VLDL, reductively glycated VLDL and non-reductively glycated VLDL respectively, separated by sodium dodecyl sulphate polyacrylamide tube gel electrophoresis ( $3 \%$ acrylamide)
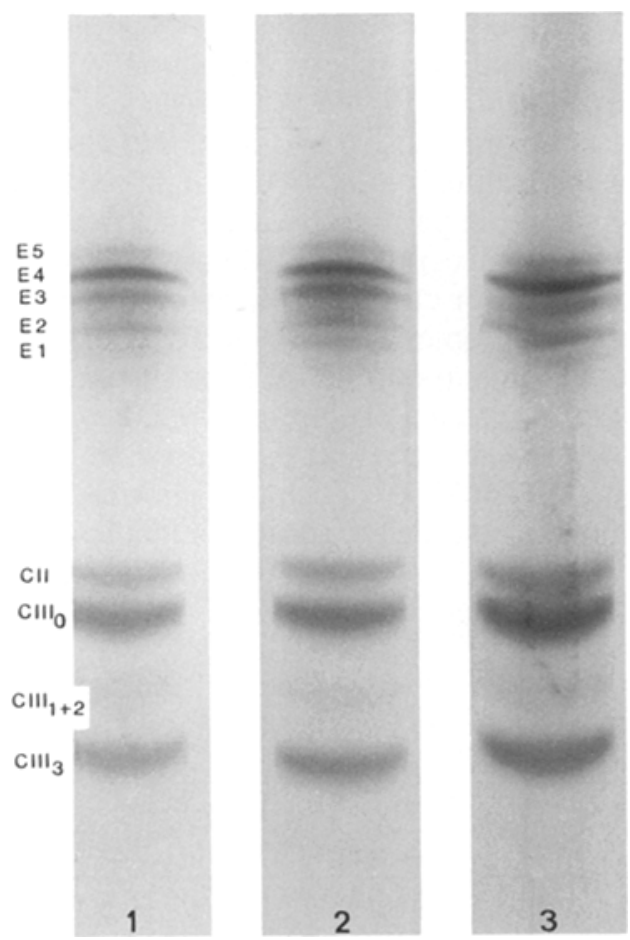

Fig. 7. Isoelectric pattern of VLDL apoproteins in 7\% acrylamide tube gels. Lanes 1-3 represent apoproteins from normal VLDL, reductively glycated VLDL and non-reductively glycated VLDL respectively

used as a measure of particle removal. Table 4 lists the MRT of triglyceride and apoprotein B for the three types of VLDL. The MRT of triglyceride and apoprotein $B$ for reductively glycated VLDL were found to be much greater than that of normal VLDL. Similarly the MRT's of non-reductively glycated VLDL tended to be longer than those of normal VLDL. Correlation of the VLDL-triglyceride MRT with apoprotein B MRT showed that for normal VLDL, triglyceride removal was independent of particle clearance (correlation coefficient $r=0.12$ ). On the other hand, both types of glycated VLDL exhibited a triglyceride clearance which correlated with apoprotein B removal ( $r=0.95$ and $r=0.72$ for reductively glycated VLDL and non-reductively glycated VLDL respectively).

\section{Glucose incorporation into VLDL apoproteins}

Apoproteins regulate the catabolism of lipoproteins and so to determine how the glycation procedure may potentially alter these, we incubated VLDL with $\left[{ }^{3} \mathrm{H}\right]$-glucose, separated the various VLDL apoproteins by SDS-PAGE and IEF and measured the amount of radioactive glucose incorporated into each apoprotein. Total apoproteins were first separated on 3-10\% polyacrylamide gels. No difference in banding patterns was observed between treatments. VLDL-glycated in the presence of a reducing agent had $27 \%$ of the radioactivity associated with apoprotein B whilst VLDL glycated in the absence of reducing agent had $40 \%$ of radioactivity associated with apoprotein $B$. The majority of the $\left[{ }^{3} \mathrm{H}\right]$-glucose was found associated with the soluble protein bands (E's and C's). To resolve the distribution of glucose radioactivity amongst the apoproteins in greater detail, isoforms of apoprotein $\mathrm{B}$ and apoproteins $\mathrm{E}$ and $\mathrm{C}$ were separated by $3 \%$ SDS-PAGE (Fig.6) and by IEF (Fig.7), respectively. Radioactivity was distributed equivalently between the

Table 3 a. The "apparent $\mathrm{K}_{\mathrm{m}}$ " for post-heparin plasma lipoprotein lipase and hepatic lipase with normal and glycated VLDL-triglyceride

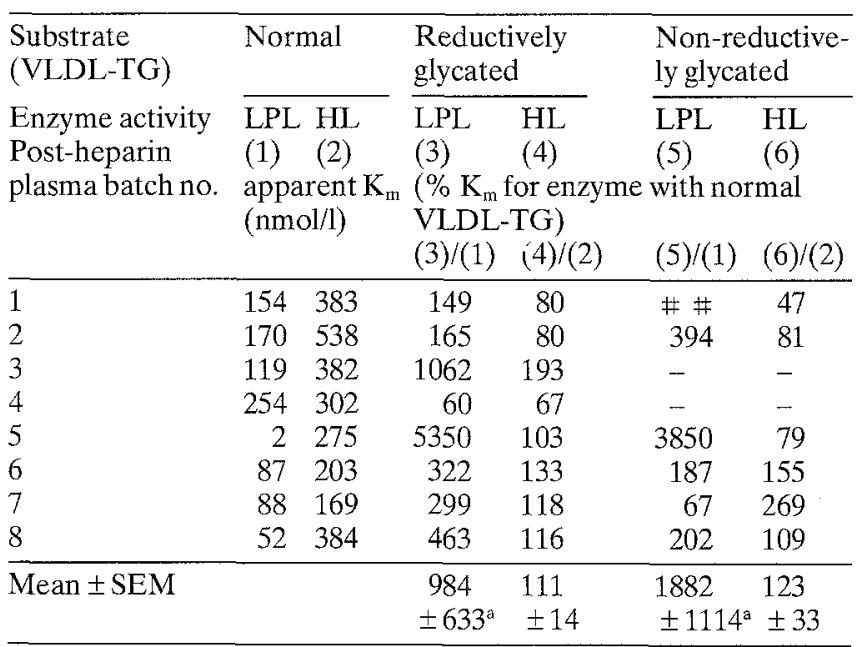

Control and glycated VLDL were incubated at increasing concentrations with post-heparin plasma lipases. "Apparent $\mathrm{K}_{\mathrm{m}}$ " for lipoprotein lipase (LPL) and hepatic lipase (HL) was determined by analogy to Michaelis-Menten kinetics (Fig.5). The "apparent $\mathrm{K}_{\mathrm{m}}$ " for glycated VLDL is shown as a percentage of that obtained for the normal VLDL. "denotes significance at $p<0.05$ vs normal VLDLtriglyceride. \# denotes that "an apparent $\mathrm{K}_{\mathrm{m}}$ " could not be derived 
Table 3 b. The "apparent $V_{\max }$ " for post-heparin plasma lipoprotein lipase and hepatic lipase with normal and glycated VLDL-triglyceride

\begin{tabular}{|c|c|c|c|c|c|c|}
\hline \multirow{2}{*}{$\begin{array}{l}\text { Substrate } \\
\text { (VLDL-TG) } \\
\text { Post-heparin } \\
\text { plasma batch no. }\end{array}$} & \multicolumn{2}{|c|}{ Normal } & \multicolumn{2}{|c|}{$\begin{array}{l}\text { Reductively } \\
\text { glycated }\end{array}$} & \multicolumn{2}{|c|}{$\begin{array}{l}\text { Non-reductively } \\
\text { glycated }\end{array}$} \\
\hline & $\begin{array}{l}\text { LPL } \\
\text { (1) }\end{array}$ & $\begin{array}{l}\mathrm{HL} \\
(2)\end{array}$ & $\begin{array}{l}\text { LPL } \\
(3)\end{array}$ & $\begin{array}{l}\mathrm{HL} \\
(4)\end{array}$ & $\begin{array}{l}\mathrm{LPL} \\
(5)\end{array}$ & $\begin{array}{l}\mathrm{HL} \\
(6)\end{array}$ \\
\hline & \multirow{2}{*}{\multicolumn{2}{|c|}{$\begin{array}{l}\text { apparent } V_{\max } \\
\text { (nmol/min) }\end{array}$}} & \multicolumn{4}{|c|}{$\begin{array}{l}\text { (\% } V_{\max } \text { for enzmye with normal } \\
\text { VLDL-TG) }\end{array}$} \\
\hline & & & $(3) /(1$ & $(4) /(2)$ & $(5) /(1)$ & $(6) /(2)$ \\
\hline 1 & 912 & 684 & 79 & 78 & \#\# & 63 \\
\hline 2 & 866 & 984 & 106 & 71 & 218 & 72 \\
\hline 3 & 345 & 415 & 266 & 63 & - & - \\
\hline 4 & 674 & 340 & 42 & 75 & - & - \\
\hline 5 & 289 & 407 & 55 & 135 & 125 & 107 \\
\hline 6 & 306 & 321 & 57 & 140 & 108 & 155 \\
\hline 7 & 436 & 247 & 86 & 155 & 66 & 221 \\
\hline 8 & 271 & 311 & 111 & 126 & 115 & 116 \\
\hline Mean $\pm \mathrm{SEM}$ & & & $100 \pm$ & $5105 \pm 1$ & $3126 \pm 2$ & $122 \pm 24$ \\
\hline
\end{tabular}

Control and glycated VLDL were incubated at increasing concentrations with post-heparin plasma lipases. "Apparent $V_{\max }$ " for lipoprotein lipase (LPL) and hepatic lipase (HL) was determined by analogy to Michaelis-Menten kinetics (Fig. 5). The "apparent $V_{\max }$ " for glycated VLDL is shown as a percentage of that obtained for the normal VLDL. \#\# denotes that "an apparent $V_{\max }$ " could not be derived

apoprotein $B$ isoforms of reductively glycated VLDL. On the other hand, VLDL apoprotein B glycated in the absence of $\mathrm{NaCNBH}_{3}$ had $49 \%$ of radioactivity with $\mathrm{B} 48$. The apoprotein B100 and B 95 contained $37 \%$ and $24 \%$ of the total apoprotein $\mathrm{B}$ radioactivity. The two main soluble apoproteins namely $\mathrm{E}$ and $\mathrm{C}$ were associated with essentially an equivalent proportion of the radioactivity $(50 \%$ each for reductively glycated VLDL and (46\%):(54\%) (E:C) for non-reductively glycated VLDL).

\section{Discussion}

A characteristic feature of subjects with diabetes is their elevated plasma VLDL-triglyceride. In hyperglycaemic diabetic patients, the majority of glycated apoproteins are associated with VLDL [5], and so in this study we investigated whether VLDL glycation altered its catabolism in a manner which could accentuate the hypertriglyceridaemia.

Glycation was done in vitro as opposed to isolating VLDL from hyperglycaemic donors, in order to avoid other changes in the physical and/or chemical nature of the lipoproteins. A reducing agent $\left(\mathrm{NaCNBH}_{3}\right)$ was used for one of the glycation procedures to rapidly convert the unstable Schiff base form of the glucose-amine adduct. In the presence of reducing agents a glucitollysine adduct is produced [15], by contrast to ketoamine and hemiketal forms in the absence of reducing agents [16]. Curtiss and Witztum, using monoclonal antibodies which recognize glucitollysine have demonstrated low levels of this type of residue naturally occurring in normal and diabetic individuals [16], though the significance of this is unknown. Nevertheless, we felt that it would be of value to determine whether there were any qualitative differences in terms of the catabolic indices between the Schiff base form (non-reduced) and ketoamine form (reduced) of glycated VLDL. Caution must be exercised when extrapolating kinetic data derived from lipoproteins glycated in vitro, and in rats, with that which may occur in vivo in humans, because the nature of the glucose-amine adducts and the mode of lipoprotein catabolism may differ substantially between the two species.

To establish whether glycation affected the removal of VLDL-triglyceride, the triglyceride of normal particles was endogenously radiolabelled, glycated in vitro and then injected into normal recipient rats. The rate of decline in plasma triglyceride radioactivity was then used as a measure of clearance. Both forms of glycated VLDL were found to have a half-life significantly longer than that of saline incubated control VLDL. This indicated that glycation impaired the removal of triglyceride in vivo.

A delay in lipoprotein triglyceride removal could be related to two separate mechanisms. One could involve impairment of triglyceride hydrolysis. The other could be related to a defect in removal of the particle itself. In order to determine if glycation of the VLDL altered the ability of VLDL-triglyceride to serve as a substrate for these lipases, we studied some of their kinetic characteristics. Lipase rich PHP was used as the source of lipoprotein and hepatic lipase. The lipoprotein lipase "apparent $\mathrm{K}_{\mathrm{m}}$ " was found to be much higher for both types of glycated VLDL. No significant trend was established for the $\mathrm{V}_{\max }$ determinations and so the data led us to conclude that the glycated particles were not as good substrates to the action of lipoprotein lipase.

VLDL-triglyceride may also remain in the plasma compartment for an extended period of time if the particle removal processes are impaired. To examine this we radiolabelled VLDL-triglyceride and VLDL-apoproteins with a different isotope for each, and injected these into normal recipients. The removal of radioactivity associated with triglyceride and apoprotein B from the plasma compartment was then calculated. Normal VLDL-triglyceride was removed in a manner that was independent of particle removal. This would be expected in a normal animal where the lipolytic cascade is of primary significance. In contrast, the data for glycated VLDL showed that in addition to VLDL-triglyceride, apoprotein B removal

Table 4. The mean residence time of normal and glycated VLDL apoprotein $\mathrm{B}$ and triglyceride in normal rats

\begin{tabular}{lrcr}
\hline & & \multicolumn{2}{c}{ Mean residence time (min) } \\
\cline { 3 - 4 } & & (Apoprotein B) & (Triglyceride) \\
\hline Normal VLDL & $(10)$ & $16.87 \pm 4.79$ & $19.23 \pm 4.79$ \\
$\begin{array}{l}\text { Reductively } \\
\text { glycated VLDL }\end{array}$ & $(5)$ & $137.31 \pm 49.13^{\mathrm{b}}$ & $213.19 \pm 87.04^{\mathrm{c}}$ \\
$\begin{array}{l}\text { Non-reductively } \\
\text { glycated VLDL }\end{array}$ & $(10)$ & $46.98 \pm 15.38$ & $50.40 \pm 18.52^{\mathrm{a}}$ \\
\hline
\end{tabular}

VLDL was radiolabelled for triglyceride and for apoprotein B with different isotopes. VLDL was glycated with glucose in the presence or absence of a reducing agent. Clearance of VLDL was monitored in normal recipient rats. $(n)=$ number of recipient animals. $\mathrm{N} \pm \mathrm{SEM} . \quad{ }^{\mathrm{a}, \mathrm{b}}$ and ${ }^{c}$ denote significance vs normal VLDL at $p<0.05, p<0.01$ and $p<0.001$, respectively 
(i.e., particle clearance) was delayed. In fact, the clearance of glycated VLDL-triglyceride correlated very strongly with the removal of the whole particle. We are unable to distinguish whether the delayed particle clearance merely reflects the impaired lipolysis of VLDL-triglyceride, or whether the glycation itself interferes with receptor and non-receptor removal mechanisms. In support of the latter, Turk and Skrabalo [17] demonstrated that VLDL glycated in vitro in a manner not disimilar to ours impaired high affinity binding and degradation by human skin fibroblasts. Furthermore, LDL glycation to an extent comparable to that occurring in diabetic patients $(2-5 \%$ glycated lysine residues) decreased the lipoprotein clearance in guinea pigs by $5-25 \%$ [18] and also in man [19].

The sites of apoprotein glycation may differ depending on the methods employed [20]. In order to explore how the glycation of apoproteins may have related to the catabolism of VLDL-triglyceride, we determined the incorporation of radioactive glucose into each of the major apoproteins. Apoprotein B was substantially glycated though the soluble proteins (E's and C's) were found to contain the majority of the radioactive glucose. The receptor binding region of apoprotein $\mathrm{E}$ is glycatable [21] and so the very long plasma residency time of glycated VLDL may reflect an impairment in receptor mediated removal. One can predict that apoproteins AI, AII and C would have highly reactive groups for glycation [15]. We found that the $\mathrm{C}$ apoproteins contained about $35 \%$ of the total glucose-amine adducts for both types of glycated VLDL. We were unable to distinguish in this study which of the $\mathrm{C}$ isoforms were glycated, however, it may be that if CII/CIII bound glucose, then the lipoprotein lipase-VLDL interaction may be altered.

In conclusion, we have presented data which demonstrate that glycation of VLDL impairs removal of it's main lipid, triglyceride and delays clearance of the particle as a whole. Thus, glycation in vivo may be a contributing factor to the hypertriglyceridaemia observed in subjects with diabetes mellitus. Coupled with reports that glycated LDL are cleared by scavenger pathways and glycated HDL are cleared more rapidly, glycation may exacerbate the pathogenesis of vascular disease amongst diabetic patients.

Acknowledgements. J. Mamo at the time of this study was a fellow of the Canadian Diabetes Association. This work was supported by the Heart and Stroke foundation of Ontario.

\section{References}

1. Garcia MJ, McNamara PM, Gordon T, Kannell WB (1974) Morbidity and mortality in diabetics in the Framingham population. Diabetes 23: 105-111

2. Drevon CA, Attie AD, Pangburn SH, Steinberg D (1981) Metabolism of homologous and heterologous lipoproteins by cultured rat and human skin fibroblasts. J Lip Res 22: 37-46

3. Sasaki J, Cottman GL (1982) Glycosylation of LDL decreases its ability to interact with high affinity receptors of human-fibroblasts in vitro and decreases its clearance from rabbit plasma in vivo. Biochim Biophys Acta 713: 199-207
4. Schleicher E, Deufel T, Wieland OH (1981) Nonenzymatic glucosylation of human serum lipoproteins. FEBS Lett 129: 1-4

5. Curtiss L, Witztum JL (1985) Plasma apolipoproteins AI, AII, B, $\mathrm{CI}$ and $\mathrm{E}$ are glucosylated in hyperglycemic diabetic subjects. Diabetes 34: 452-461

6. Hirano T, Mamo J, Poapst M, Steiner G (1988) Very low density lipoprotein triglyceride kinetics in acute and chronic carbohydrate-fed rats. Am J Physiol 255: E236-240

7. Fidge $\mathrm{NH}$, Poulis $\mathrm{P}$ (1974) Studies on the radioiodination of very low density lipoprotein from different mammalian species. Clin Chim Acta 52:15-26

8. Egusa G, Brady DW, Grundy SM, Howard BV (1983) Isopropanol precipitation method for the determination of apolipoprotein $B$ specific activity and plasma concentrations during metabolic studies of very low density lipoprotein apolipoprotein B. J Lip Res 24: 1261-1267

9. Witztum JL, Mahoney EM, Brinks MJ, Fisher M, Elam R, Steinberg D (1982) Nonenzymatic glucosylation of low-density lipoprotein alters its biological activity. Diabetes 31: 283-291

10. Herbert PN, Shulman RS, Levy RI, Frederickson DS (1973) Fractionations of the C-apoproteins from human plasma very low density lipoproteins. J Biol Chem 248: 4941-4946

11. Poapst M, Uffelman K, Steiner G (1987) The chromogenicity and quantitation of apo-B100 and apo-B48 of human plasma lipoproteins on analytical SDS gel electrophoresis. Atherosclerosis $65: 75-88$

12. Reardon MF, Poapst M, Steiner G (1982) The independent synthesis of intermediate density lipoproteins in Type III hyperlypoproteinemia. Metabolism 31: 421-427

13. Korn ED (1955) Clearing factor, a heparin activated lipoprotein lipase. I. Isolation and characterization of the enzyme from normal rat heart. J Biol Chem 215: 1-14

14. Yamada N, Havel RJ (1986) Measurement of apolipoprotein B radioactivity in whole blood plasma by direct precipitation with isopropanol. J Lip Res 27: 910-912

15. Means GE, Chang MK (1982) Nonenzymatic glycosylation of proteins. Structure and function changes. Diabetes $31: 1-4$

16. Curtiss LK, Witztum JL (1983) A novel method for generating region-specific monoclonal antibodies to modified proteins. Application to the identification of human glucosylated low density lipoproteins. J Clin Invest 72: 1427-1438

17. Turk Z, Skrabalo Z (1987) The cell-interactive properties of glucosylated very-low-density and low-density lipoproteins. Cell Mol Biol 33: 345-354

18. Steinbrecher U, Witztum JL (1984) Glucosylation of low-density lipoproteins to an extent comparable to that seen in diabetes slows their catabolism. Diabetes 33: 130-134

19. Witztum JL, Steinbrecher UP, Fisher M, Kesaniemi A (1983) Nonenzymatic glucosylation of homologous low density lipoprotein and albumin renders them immunogenic in the guinea pig. Proc Natl Acad Sci USA 80: 2757-2761

20. Shapiro R, Mcmanus MJ, Zalut C, Bunn HF (1980) Sites of nonenzymatic glycosylation of human hemoglobin A. J Biol Chem 255:3120-3127

21. Fluckiger R (1985) Glycosylation of lipoproteins: chemistry and biological implications. Monogr Atheroscler 13: 53-62

Received: 29 September 1989

and in final revised form: 27 February 1990

Dr. J.Mamo

Department of Physiology

University of Western Australia

Stirling Highway

Nedlands, Perth, 6009

Australia 